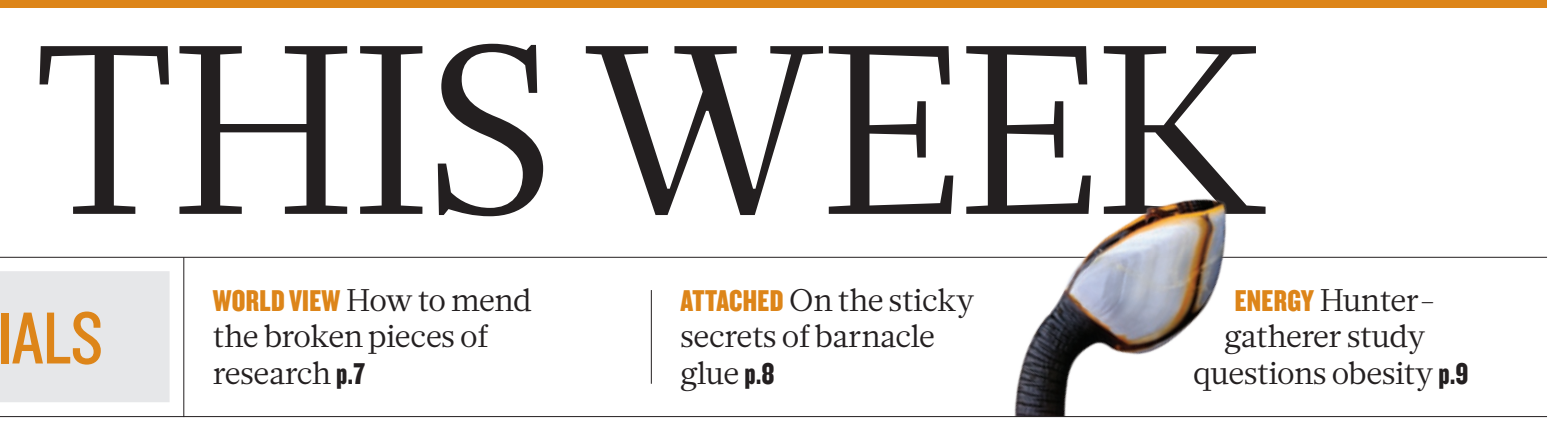

EDITORIALS the broken pieces of research $\mathbf{p . 7}$ secrets of barnacle glue $\mathbf{p} . \mathbf{8}$

\title{
Accountable and transparent
}

\author{
The US government has changed how biomedical scientists disclose their financial interests. The \\ revised rules are welcome, but Internet access to the identified conflicts should be a requirement.
}

$\mathrm{T}$ Toughened rules for how US biomedical scientists report financial interests came into force last month. The changes, which affect scientists who receive grants from the government, are welcome - although in one respect they do not go far enough.

About 38,000 researchers, most of them recipients of grants from the US National Institutes of Health (NIH), the world's largest medical-research funder, will need to comply with the beefed-up rules. The changes update regulations put in place in 1995 to ensure that investigator bias doesn't sway the design, conduct or reporting of research.

There are several important changes. First, investigators must now disclose to their institutions every "significant financial interest" belonging to themselves or their immediate family that is related to any of their institutional responsibilities - from teaching and seeing patients to lab research and service on ethics committees. This requirement appropriately casts a broader net than the previous rules, which generally asked for disclosure on only a project-specific basis.

The change ends ambiguity that, for instance, might have allowed a researcher to conclude that paid service on the board of a major pharmaceutical company drew only on clinical expertise, and therefore was not relevant to a government-funded research project that used one of the company's experimental compounds. Under the updated rules, there will be no question that such income must be disclosed, and institutions will have a more complete picture of their scientists' potentially relevant financial interests.

It takes only one example to drive home the significance of this change. Between January 2000 and January 2006, high-profile psychiatrist Charles Nemeroff, then at Emory University in Atlanta, Georgia, received more than US\$800,000 in payments from drugmaker GlaxoSmithKline for over 250 speeches that he gave to psychiatrists. He failed to disclose this income to Emory administrators. After being discovered, Nemeroff argued that the rules on whether such income was reportable were ambiguous.

The tougher rules, crucially, give institutions prime responsibility for determining whether a given financial interest - companypaid speaking honoraria, consulting fees, paid authorship, travel reimbursements and stock ownership all qualify — is related to a government-funded grant, and whether it constitutes a conflict. Under the old regime, the scientist was charged with deciding whether a given interest was related to the research and thus whether it was reportable. That arrangement did not inspire confidence - a problem in an era in which public trust in the medical enterprise is at risk and must be built, not undermined.

The updated rules also lower the threshold at which an interest is defined as significant, from $\$ 10,000$ under the old rules to $\$ 5,000$. In a moribund economy with many US taxpayers struggling to make ends meet, this is fitting.

The rules have also been strengthened in other important ways.
For instance, far more detail will now be reported by institutions to the NIH about each identified conflict, including the approximate dollar value of the interest and the measures being taken to manage or eliminate the conflict. There is also, importantly, an explicit exception to the disclosure requirements for income that scientists earn from universities or government agencies for teaching, serving on advisory or review panels and giving seminars or lectures.

The new rules fall down, however, in one significant regard. When
"Public trust in the medical enterprise is at risk and must be built, not undermined." it first published the proposed changes, the $\mathrm{NIH}$ described what it called "an important and significant new requirement to ... underscore our commitment to fostering transparency, accountability, and public trust”.

That requirement was that institutions would post details of their investigators' financial conflicts of interest on a publicly accessible website that was updated every year. In the final iteration of the new rules, the website has been made optional, and institutions faced with requests for information may instead respond in writing, within five business days. This is an outdated approach to transparency. It will not advance the public's faith in timely, comprehensive and truly accessible disclosure, at a time when the boundary between academia and industry has become ever more porous, and when the average citizen's trust in government-funded medical research is ever more crucial. The NIH should revise the rules again to make the website mandatory. It is within the agency's power to insist on this standard, and it is the right thing to do. $\square$

\section{Spinning threads}

\section{Publication of ENCODE data drives innovation in data mining.}

$\mathrm{T}$ There can be few scientists who have not used a brightly coloured highlighter pen to mark the most interesting parts of a research paper, report, proposal or (librarians look away) book. It is a natural reaction when faced with a swamp of information - to build islands of focus that can be identified and linked, both in print and in the mind.

This week, Nature introduces a new concept in the publishing and dissemination of scientific information: one that is a response to the increasing complexity of modern research, and one that draws heavily on the contribution of the humble highlighter.

Starting on page 45 , we publish a package of material that centres 